[ MÔNICA MOURA ]

Doutora em Comunicação e Semiótica. Pesquisadora, professora e consultora em design. Coordenadora do Grupo de Pesquisa Design: Criação e Novas Mídias, vinculado ao CNPq e ao Centro de Pesquisa em Design e Moda do Mestrado em Design da Universidade Anhembi Morumbi. Autora de vários artigos e publicações sobre design contemporâneo, ensino e novas mídias, entre elas, o e-book Design de hipermidia: dos princípios aos elementos (NMD/Rosari, 2007) e organizadora do livro Faces do design $1 \mathrm{e}$ 2 (Rosari, 2003, 2009). E-mail: monica@anhembi.br

[1] Hotel Quo Godoy, Business Center, Madri

[2] Hotel Quo Godoy, Hall de entrada, Madri

[3] Hotel Jerônimos 8 , Hall do restaurante, Lisboa

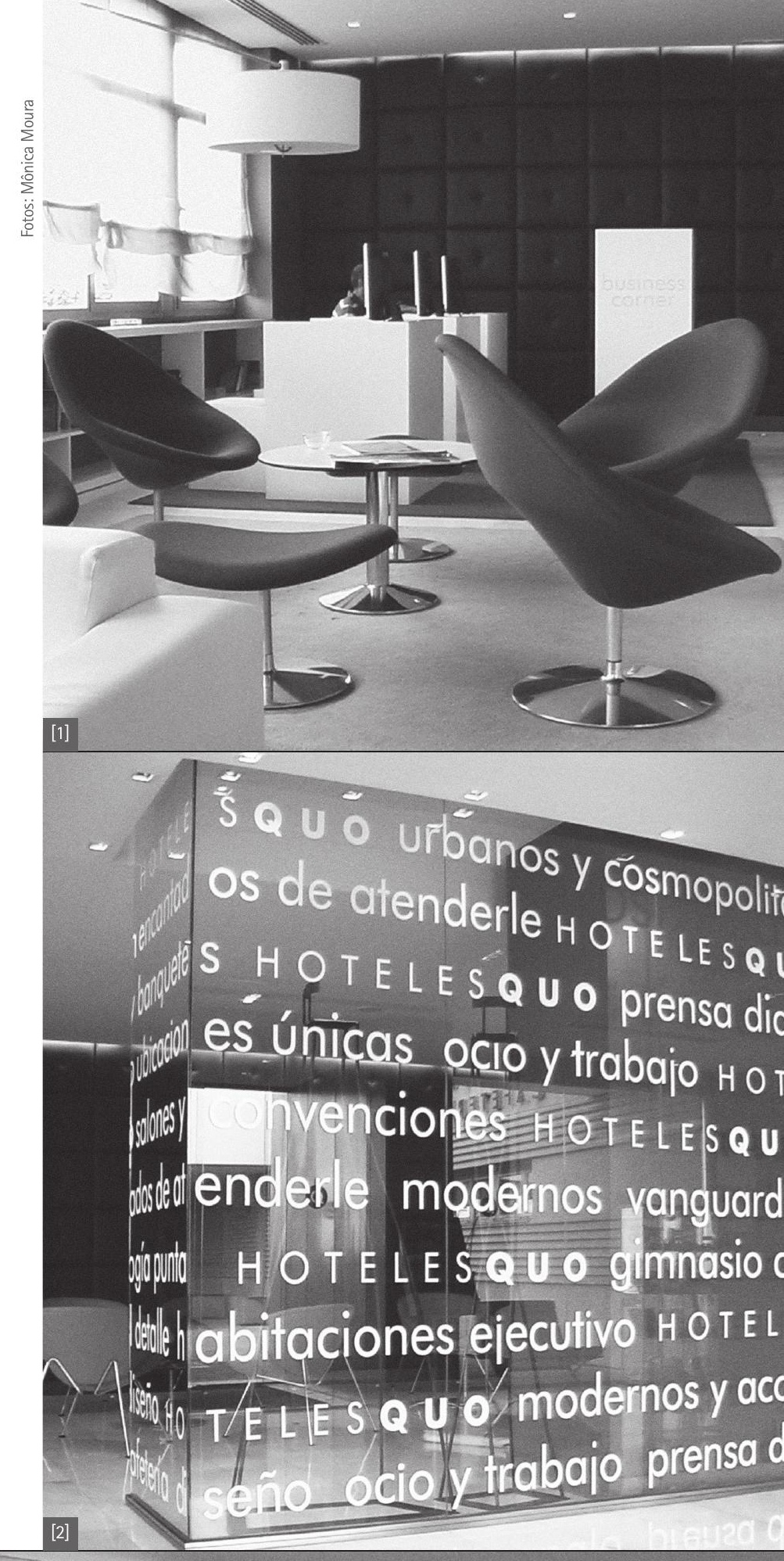

[3]

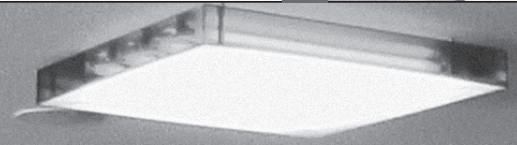




\section{Hotéis de design: expressoes do contemporâneo}

Cada vez mais o design se insere em nosso cotidiano e se encontra presente em praticamente tudo o que nos cerca. Prova disso é que vemos surgir a todo instante segmentos intitulados como "de design" ou "com design", seja em produtos, seja em serviços. Parece que essas designações são empregadas de forma que a nomenclatura ou a palavra "design" agregue e demonstre valores diferenciados, muitas vezes de forma indiscriminada e como puro apelo de marketing ou publicidade. Mas encontramos propostas que utilizam a designação design respeitando seu real significado e aplicação. É o caso dos hotéis de design que são impregnados do discurso contemporâneo, incluindo evidentemente o do consumo. É sobre eles que vamos falar nesta edição do segundo aniversário de dObra[s]. Queremos comemorar convidando e propondo a todos viagens a territórios que exploram das maneiras mais diversas a sensibilidade, a criatividade e a irreverência.

\section{Projetando hotéis de design: conceito, sensações e funcionalidade}

John Heskett' $(2002,2008)$ afirma que o design, em sua essência, pode ser definido como a exploração da capacidade humana de moldar o nosso ambiente em todos os seus detalhes para servir às nossas necessidades e dar significado às nossas vidas. 0 design, portanto, é elemento determinante na (e para a) qualidade de vida das pessoas!

$\mathrm{Na}$ exposição Paris de Patrick Jouin ${ }^{2}$, encontramos, em meio a vários projetos, produtos e objetos que fazem parte da vida cotidiana criados e desenvolvidos por esse designer. Entre eles, destacamos uma instalação da suite de hotel denominada Wow Extreme, projeto conceitual desenvolvido para W Hotéis Worldwide. A proposta é a de um concept room e apresenta uma suite do futuro próximo. Esse projeto coloca em prática uma forma de pensar sobre os modos de vida contemporânea em que a pluralidade, 0 acesso à informação, a mobilidade, a transitoriedade, o explorar das sensações e a estética são determinantes e modificaram os comportamentos, as expectativas e os desejos das pessoas, principalmente quando estas se encontram no papel de clientes e usuários, utilizando um senviço, como é o caso dos hotéis - locais de uso transitório e efêmero.

0 exercício do projeto da suíte Wow Extreme demonstra e coloca em prática o processo do design, bem como explora a definição de seus autores, o designer Patrick Jouin e o arquiteto Sanjit Manku. Para eles, design é "um acréscimo de pensamento crítico, de instinto e capacidade artistica misturados à cultura e ao mundo dos negócios" (GUILLAUME, 2009, p. 49).

A suíte Wow Extreme apresenta diferentes áreas reunidas em um espaço único e integradas em $100 \mathrm{~m}^{2}$. Estar, trabalhar, comer e beber, vestir, cuidar do corpo e banhar, descansar e dormir são funções básicas que um hotel deve oferecer na atualidade. No projeto de Jouin, essas questões são exploradas de forma diferenciada e associadas a outras funções, como a de experimentar, receber, divertir, sentir. A suite também foi projetada para que o hóspede fique impregnado pelo modo de vida do local, neste caso específico, a art de vivre à francesa.

$\mathrm{Na}$ área denominada Rede social, virtual e real, a diversão, o lazer, a interatividade e a conectividade são enfocados. Equipamentos de alta definição possibilitam a exibição de shows, videoclipes, filmes e games, no mesmo local onde um confortável sofá modulado e o espaço disponivel permitem receber até 15 pessoas para uma festa ou um encontro de amigos. Além disso, essa área é composta por sistema interativo de comunicação e informação com os serviços do hotel e acesso à internet.

No centro do espaço da suíte encontramos o minibar e a minicozinha integrados e muito próximos à banheira. 0 bar e a cozinha permitem degustar, explorar e experimentar a culinária, a água e as bebidas locais, inclusive, enquanto você estiver tomando um demorado banho de sais e ervas. Em frente da grande banheira, há uma parede com projeção de modo a somar a este espaço de relaxamento e sensações o divertimento e 0 entretenimento.

A área de vestir é composta por um armário aberto onde há roupas de marcas e criadores locais. As peças estão disponiveis ao uso dos clientes para que o hóspede não necessite levar grandes bagagens. Imagine encontrar no quarto do hotel roupas 
desenvolvidas para se adaptar a diversos estilos, que você pode usar durante a sua estada e também comprar as que você mais gostou.

Em uma pequena área próxima ao espaço de vestir localiza-se a área de trabalho, uma mesa-escrivaninha, com dispositivos de acesso à rede e telefonia.

$\mathrm{Na}$ área de descanso há uma grande e confortável cama e uma chaise-longue para leituras. Nesse local, abajures Nightcove têm um sistema denominado Zyken que possibilita relaxar, dormir e acordar a partir de diferentes gradações de cores, sons e luzes.

Em toda a suíte está presente o projeto pensado e desenvolvido para explorar sensações e apreender o espaço e as áreas por meio de iluminação, formas e texturas. 0 sistema de iluminação de todas as áreas da suite permite optar por diferentes variações de intensidade e coloração das luzes, de forma direta e indireta. 0 carpete foi desenvolvido em planos de alturas e texturas variadas a fim de delimitar e permitir que o hóspede identifique a área na qual se encontra no espaço da suíte.

0 todo desse projeto permite que experiências sensiveis sejam exploradas pelo usuário em uma suíte de hotel. Esta se estabelece como uma interface entre o privado e o urbano em uma marca de hotel que investe em uma proposta estética e inovadora utilizando o design em toda a sua amplitude.

\section{Redes de hotéis de design}

Existem redes que têm como proposta principal o design. Vou falar aqui de três que conheci em viagens recentes. Uma chamada Hoteles Quo, a outra denominada 987hotels\# e a terceira, pioneira neste segmento e existente no mercado há dezesseis anos, Design Hotels. A primeira conta com cinco hotéis em Madri, a segunda, com três hotéis nas cidades de Barcelona e Praga e a terceira, com 160 hotéis presentes em 40 paises e distribuídos entre Europa, Ásia, África e Américas. No Brasil, até o momento, apenas um hotel pertence a esta rede, o Unique, localizado na cidade de São Paulo.

0 Unique tem o projeto de arquitetura desenvolvido por Ruy Ohtake, o de interiores por João Armentano e o paisagismo por Gilberto Elkis. Sem dúvida, a localização, os espaços internos e externos, e os serviços são dignos de um lugar de irreverência e sofisticação. Mas os altos custos de uma hospedagem situam o design em uma plataforma do luxo e do acessivel a poucos, fato que não ocorre com todos os hotéis pertencentes às outras redes de hotéis de design.

\section{Viajando por alguns hotéis de design}

Um hotel de design atua no sentido maior do que vem a ser o design contemporâneo. 0 projeto de design, no seu significado mais amplo, é utilizado desde a concepção do espaço até a máxima integração da arquitetura com o design de interiores, o design gráfico, digital e de produto, as artes e, também, a moda. Além disso, a presenvação histórica, a preocupação com o entorno e as expressões artísticas são questões sempre presentes.

Esses hotéis têm como proposta atingir o máximo do conforto, a facilidade de acesso às informações e comunicação por meio das tecnologias empregadas e o desenvolvimento sustentável. É a máxima do design, campo responsável por desenvolver de forma interdisciplinar os sistemas de informação e de configuração dos espaços e objetos materiais ou imateriais que constituem a vida do homem visando ao conforto e ao bem-estar.

0 Hotel Quo Godoy em Madri, da rede de mesmo nome, tem o espaço externo determinado por uma arquitetura de linhas retas e blocos horizontais; já o interno apresenta a integração por meio de diversos ambientes. Jardins são demarcados por canteiros retilíneos pintados de branco, contrastando com a cor lilás das lavandas plantadas em toda a extensão dos canteiros. Esses pequenos jardins integram cada apartamento com iluminação indireta e confortável. As cores, as formas, os aromas, o mobiliário e os objetos com ícones de designers consagrados compõem os espaços. No entanto, há que se destacar que esta rede é composta de hotéis para o viajante que está a trabalho e a negócios, ou seja, não constitui um universo de luxo, e sim faz parte do universo cotidiano e acessivel a um grande número de pessoas. Outro ponto muito explorado é a identidade visual e de marca, porém conservando aspectos com propostas diferenciadas e exclusivas. Por exemplo, os apartamentos e as suites são compostos de ambientes diferentes, cada qual projetado de forma exclusiva. Por outro lado, esses hotéis são constituídos com projetos pensados e desenvolvidos, desde louças, porcelanas, vidros e cristais dos objetos de serviço de restaurante e bar projetados e desenhados especificamente para a finalidade a que se destinam até a revista impressa do hotel, o web site, as embalagens dos produtos de toalete ofertados, todos seguem uma afinada unidade projetual. 
0987 Barcelona Hotel se propõe a criar experiências de design nas quais a funcionalidade e a estética se associam resultando em beleza, delicadeza, conforto e estilo, bem como conjugando expressões do passado com a irreverência do presente, objetivando 0 bem-viver e o explorar os sentidos humanos. Este hotel associa a arquitetura histórica de um prédio que foi restaurado e adaptado ao uso contemporâneo e à função de um hotel. 0 contraste de espaços, de linhas e dos ambientes com os objetos, mobiliário e sinalização é determinante para criar esse clima, além da atenção com o descanso dos hóspedes, expressa pelo cuidado com as roupas de cama, a temperatura dos apartamentos, a acústica perfeita e a área de banho, tudo foi projetado para atingir o objetivo proposto.

No Hotel Jerônimos 8 de Lisboa, pertencente à rede Design Hotels, destaca-se a valorização pelas características culturais. Este hotel se localiza no bairro histórico de Belém e é próximo ao Mosteiro dos Jerônimos, importante exemplar do estilo Manuelino. 0 mosteiro é uma das referências do partido projetual adotado para a adaptação do hotel à rede de design a partir de um prédio de 1940. Há um belo contraste entre as sacadas das varandas e a fachada externa com a parte interna do hotel. Esta é constituída por móveis e espaços de linhas retas, nos quais há predominância das cores vermelho, marrom e branco, grandes esculturas brutalistas e, no bar, fotos em branco e preto apresentam detalhes do mosteiro em leituras visuais singulares e ocupam todo o espaço das paredes onde se encontram. Há intensidade na relação entre a paisagem construída e a paisagem real. Das grandes janelas e portas de vidro do hotel pode-se observar várias áreas do mosteiro e, ao mesmo tempo, as fotos que destacam e apresentam leituras e expressões diferenciadas deste patrimônio da humanidade.

Em todos os exemplos dos hotéis de design é clara a preocupação com a sustentabilidade no uso da água e da iluminação, bem como no conforto ambiental, tanto na iluminação quanto na acústica. Também é evidente o cuidado com a comunicação visual e de sinalização para o hóspede-usuário. Indicações claras e bem selecionadas no acesso aos apartamentos, com números grandes nas portas para facilitar a localização e corredores bem demarcados, ora pelo carpete listrado, ora pela cor, ou mesmo pelo revestimento das paredes e tipo de iluminação.

Essas redes e esses hotéis de design vêm comprovar a importância dos ambientes, dos espaços e do conforto material e estético para o ser humano. Constituem ilhas de prazer e bem-estar que exploram a sensibilidade e os sentidos humanos e traduzem 0 design contemporâneo.

\section{NOTAS}

${ }^{[1]}$ Especialista e teórico em design, atualmente professor titular na Escola de Design da Universidade Politécnica de Hong Kong.

[2] A exposição Paris de Patrick Jouin, do designer francês, teve curadoria de Valérie Guillaume e foi realizada no Instituto Tomie Ohtake, em São Paulo, entre 30 de julho e 27 de setembro de 2009. Para saber mais, acesse: <www.institutotomieohtake.org.br>.

\section{REFERÊNCIAS}

DESIGN Hotels Year Book 080. Berlim: Design Hotels AG, 2008.

GUILLAUME, Valérie. Paris de Patrick Jouin. São Paulo: Instituto Tomie Ohtake, 2009. Catálogo de exposição, 30 jul. 2009-27 set. 2009, Instituto Tomie Otake.

HESKETT, John. El diseño en la vida cotidiana. Barcelona: Gustavo Gili, 2002.

Design. São Paulo: Ática, 2008.

\section{WEBGRAFIA}

www.patrickjouin.com

www.designhotels.com

www.hotelesquo.com

www.hotelunique.com.br

www.987barcelonahotel.com

www.jeronimos8.com 